\title{
Upper intestinal motility in ulcerative colitis, idiopathic steatorrhoea, and the irritable colon syndrome
}

\author{
J. A. RITCHIE AND S. N. SALEM ${ }^{1}$ \\ From the Nuffield Department of Clinical Medicine, The Radcliffe Infirmary, \\ Oxford
}

EDITORIAL SYNOPSIS This is a study on the possible motility disturbances associated with small intestinal dysfunction. Reduced luminal resistance was found to correlate with reduced xylose absorption and may be the factor most likely to influence absorption mechanically in ulcerative colitis and steatorrhoea.

The absorption of xylose has been shown to be deficient in severe ulcerative colitis (Vartio, 1963). This may be partly the result of structural changes in the mucosa of the small intestine, which have been shown to be a feature of the disease (Salem, Truelove, and Richards, 1964). On the other hand, it is known that anticholinergic drugs with their resulting decrease in intestinal motor activity may result in defects of absorption (Groisser and Farrar, 1962).

It was thought that a comparison of the motility of the small intestine in ulcerative colitis with that in other conditions, with and without evidence of malabsorption, might be used to identify any upset of muscular function consistently associated with this defect.

\section{CLINICAL MATERIAL}

In this study the levels of duodeno-jejunal activity, as estimated from intraluminal pressure records, in a group of 14 patients with ulcerative colitis have been compared with those of 24 patients with other pathological and functional conditions.

The ulcerative colitis group was composed of seven patients with mild and remittent cases and seven of moderate severity. In all of them a biopsy showed abnormalities of small-intestinal mucosa.

The comparative groups included four patients with psoriasis, five with anaemia, six with diarrhoea ascribed to the irritable colon syndrome, five who had undergone partial gastrectomy, and four with idiopathic steator-

Physician in the Kuwait Government Medical Service on study leave. rhoea. Apart from the last group, intestinal biopsies showed normal duodeno-jejunal mucosa in all cases.

\section{METHOD}

Each patient was asked to swallow a bundle of three 1-mm. radio-opaque tubes held together with latex, which were then filled with water. One of these tubes was attached to a Crosby intestinal biopsy capsule, the second had its open end $1.5 \mathrm{~cm}$. proximal to the capsule opening, and the third tube, with its outlet about $4 \mathrm{~cm}$. proximal to the capsule, was used for introducing solutions for observation.

Intraluminal pressures were transmitted by the waterfilled tubes to Shillingford-Muller transducers and recorded by means of a Cambridge three-channel directwriting recorder as described by Ritchie, Ardran, and Truelove (1962). Two channels of the instrument recorded pressures from the Crosby capsule and from the openended tube near it, while the third channel was used for a pneumograph.

The level of intestinal activity in each instance was assessed from the pressure tracings recorded through the Crosby capsule except after biopsy, when the capsule opening is closed by the blade. The pressure record had then to be taken from the open-ended tube nearby. Comparison of pressures transmitted by the capsule with those from an ordinary open-ended tube at the same point showed that the capsule was functioning satisfactorily as an open-ended tube. In each case the height, duration, and form of pressure peaks on the two tracings were almost identical over periods of an hour or more.

The patients were all observed at rest for a period averaging about 12 minutes. After that, observations were made of some patients' responses to a number of stimuli. These included the instillation into the bowel of $10 \mathrm{ml}$. lots of water, saline, certain amino-acids, ascorbic 
acid, and hypertonic glucose, and trauma when the biopsy capsule was 'fired'. The knife mechanism of the Crosby capsule is activated by suction on the tube.

In seven patients with ulcerative colitis and in seven patients from the comparison groups, parts of the pressure tracings were monitored with short periods of cineradiography. These extended to about 40 frames at one exposure per second, using a $12 \frac{1}{2}$ in. Cinelix image intensifier and pulsed radiation. The average age of these patients was 44 years, the only woman under 40 in the series being one aged 25 with ulcerative colitis who was referred by the clinicians for investigation.

Inclusive of fluoroscopy and any still radiographs, each patient received a skin dose of about $2 r$ to an area of less than $60 \mathrm{sq}$. inches. Although the conditions of exposure cannot be regarded as strictly analogous, the International Commission on Radiation Protection accepts that radiation workers may receive up to $3 \mathrm{r}$ whole-body radiation in a 13-week period. The doses employed in this study were only two-thirds of this acceptable maximum and the area exposed was less than one tenth of the body silhouette.

It should in addition be emphasized that all 38 patients, whether or not a knowledge of the state of their intestinal mucosa and motor function was necessary to the differential diagnosis in their own cases, were fully informed in advance of the potential hazards arising both from the biopsy procedure and from the radiation dosage which they were to receive.

MEASUREMENTS Measurements were made on the pressure tracing from the capsule during the whole of the resting time and for one minute after each of the stimuli.

PARAMETERS OF COMPARISON Four parameters of comparison were used for assessing duodeno-jejunal activity.

The first was the height of the largest pressure peak recorded during the period of observation. In order to compare peaks observed during the 12 minutes of the resting time with those that occurred during the single minute of the other observation periods as a direct consequence of the stimulus applied, a correction factor was needed. To find it, the mean maximum height for all groups during the last minute of the resting period was divided by that for the whole period. This gave a ratio of 10.8 to 21.8 or approximately half.

The second parameter of comparison was the proportion of each observation period during which pressure changes attributable to gut activity were transmitted through the capsule.

The third parameter was the commonest height of the pressure peaks observed. Peaks were divided into four groups, those from 0 to $5 \mathrm{~mm}$. $\mathrm{Hg}$ being group 1,5 to $10 \mathrm{~mm}$. $\mathrm{Hg}$ group 2,10 to $20 \mathrm{~mm}$. $\mathrm{Hg}$ group 3 , and over $20 \mathrm{~mm}$. $\mathrm{Hg}$ group 4. The peaks occurring in each period were counted and grouped, and the group most frequently observed during the period was recorded as representative.

The fourth parameter, limited to the resting period, was the duration of all isolated pressure peaks. Multiple peaks, whose individual components did not begin and end on the baseline of the pressure tracing, could not be measured and were excluded.

The parameters recommended for analysis of motility records at the Brussels symposium in 1964 were omitted as unsuitable, chiefly because the periods of observation following each of the stimuli were of necessity so short.

\section{RESULTS}

CINERADIOGRAPHIC STUDIES Cine- or sequence radiography showed that contractions in the upper intestinal tract might arise either spontaneously or in response to distension caused by contraction of another section. The contractions involved any length of gut from about $\frac{1}{8}$ in. to 2 in. and even a narrow one could exert a direct pressure of $40 \mathrm{~mm}$. $\mathrm{Hg}$ on the holes in the recording tube tip. Contractions were maintained for varying periods from about two seconds up to seven seconds in all groups. They served to break up the length of the small gut temporarily into functional segments of widely differing sizes.

When gut contents were displaced by the contraction of a length of bowel and were propelled into a neighbouring section, this would often contract secondarily in response to the distension. The most usual time taken to respond was four to five seconds and there were no significant differences in this respect between either mild or severe ulcerative colitis and the comparison groups (Fig. 1). The secondary interval appeared to be shorter when the distending pressure was raised (Fig. 2) and there

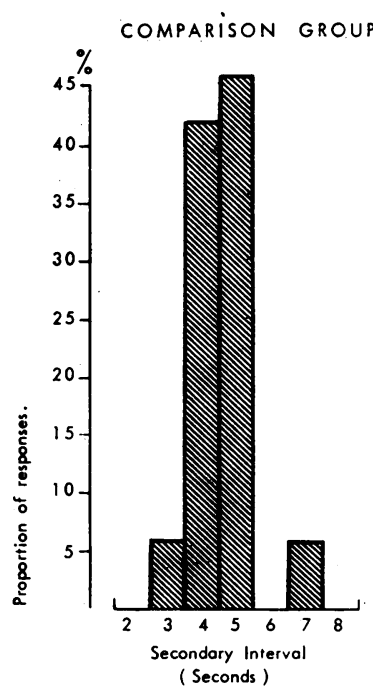

ULCERATIVE COLITIS

FIG. 1. Secondary intervals. 


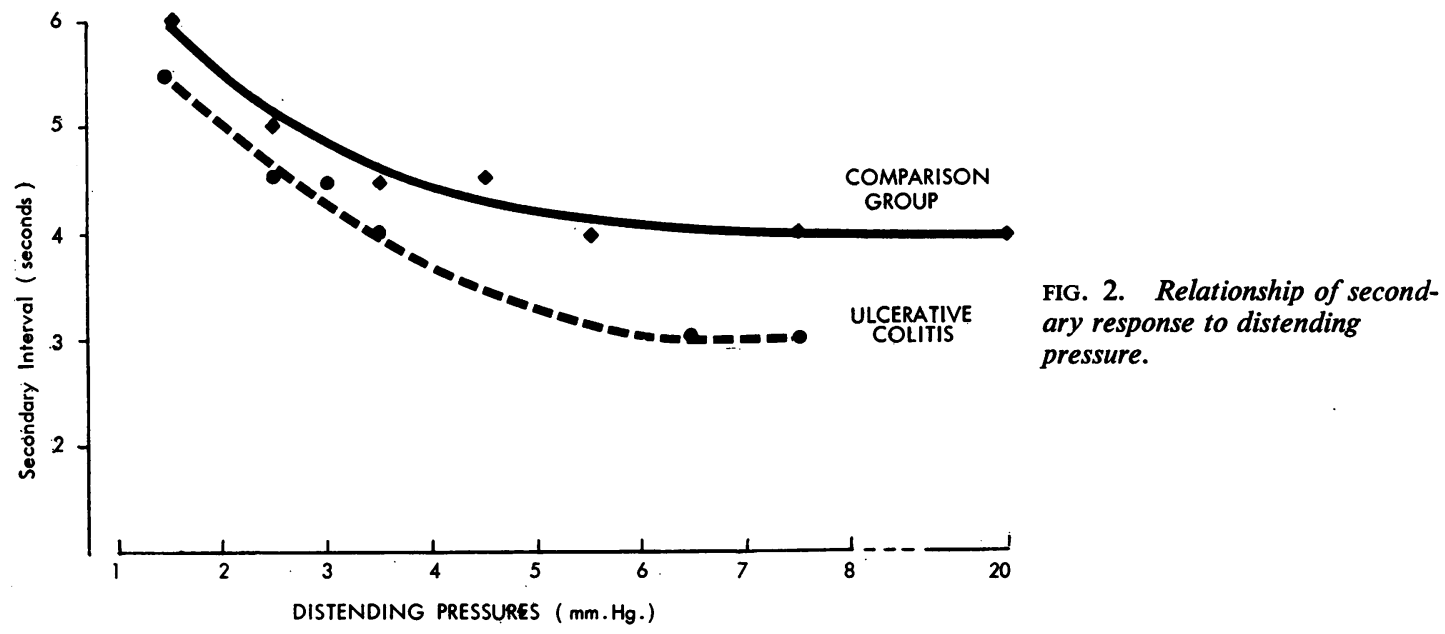

was some indication that it might be slightly shorter in ulcerative colitis than in the comparison groups for a given pressure of distension.

The functional effect of these secondary contractions was either a local shuttling to and fro of gut contents (Fig. 3) or a serial propulsive movement through two or more temporary functional segments in either direction (Fig. 4). When they were seen in any of the comparison groups, serial runs of secondary propulsion travelled at an overall rate of about one inch per second. In ulcerative colitis the rate was about $33 \%$ slower (Table I). The two forms of activity, localized and propulsive, could not be identified from a pressure tracing.

It may be worth mentioning at this juncture that these movements closely resemble those described by McLaren, Ardran, and Sutcliffe (1950) from 100 observations on 30 normal volunteers when intraluminal tubes were not used. The shuttling movements correspond to their 'non-progressive segmen-

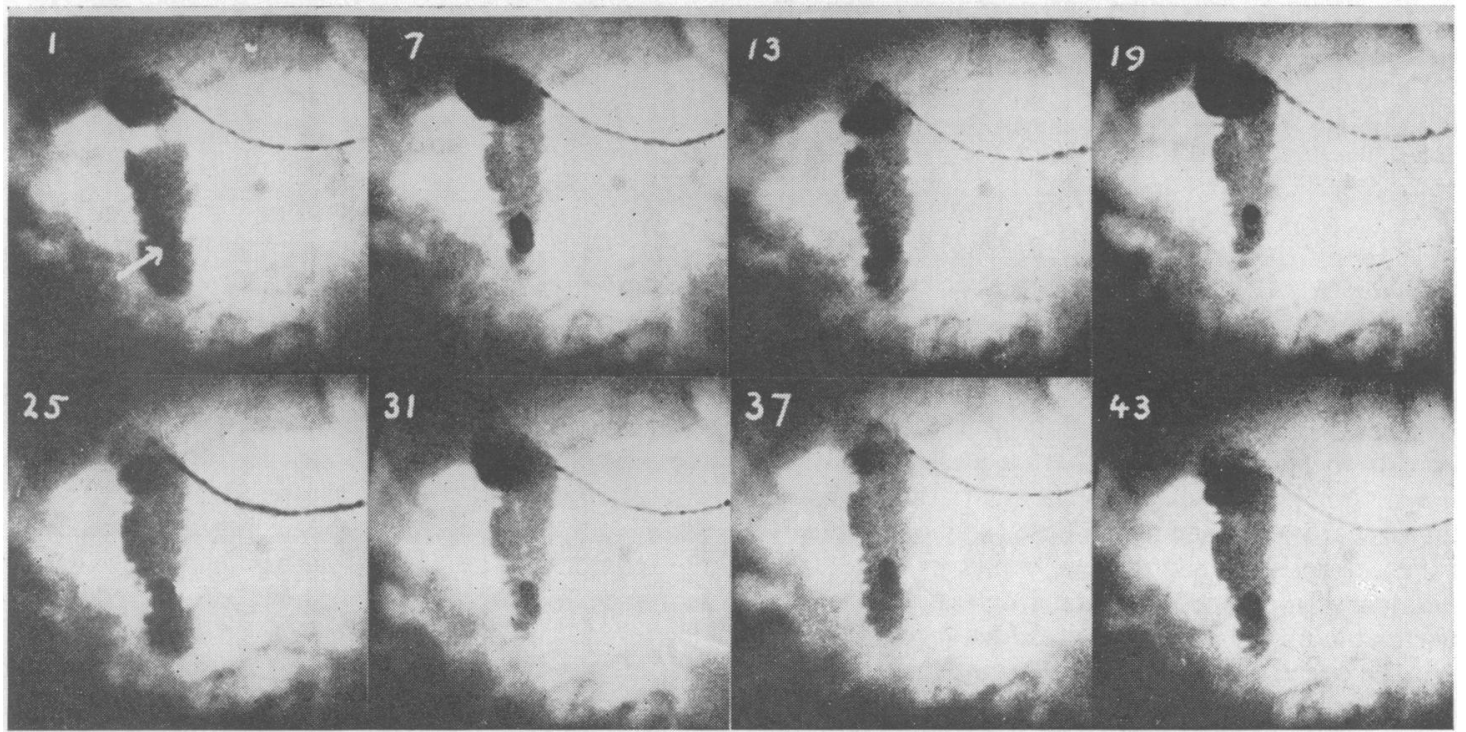

FIG. 3. Shuttling movements in the duodenum. The Crosby capsule marked by the arrow is located in the second part of the duodenum and barium suspension injected six minutes earlier is shuttled to and fro over the period of 45 seconds covered by the cine. Contraction proximally displaces barium distally and a secondary response distally after five to six seconds returns it, when the process is repeated. At no time does the intraluminal pressure exceed $2 \mathrm{~mm}$. Hg and there is insufficient propulsive force to lift the pool of barium over the vertebral column. 


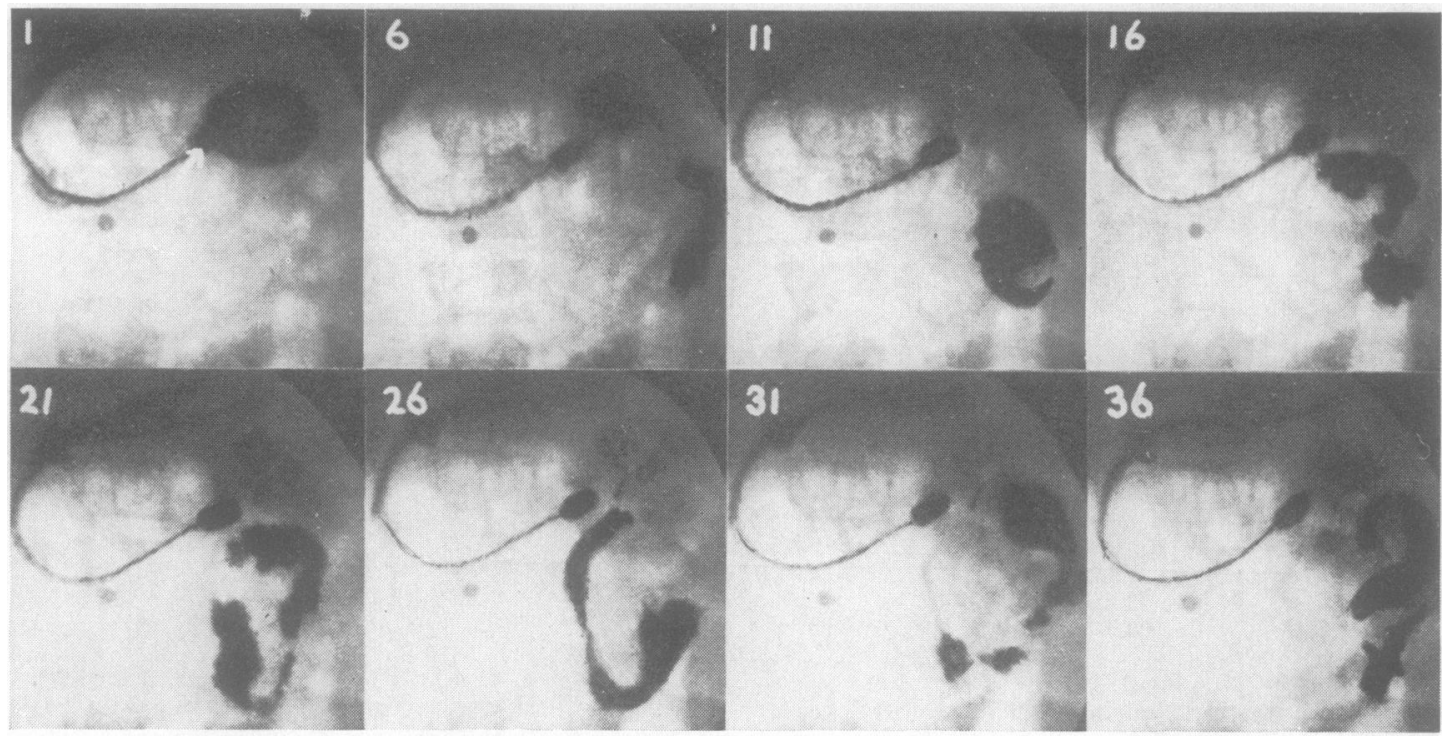

FIG. 4. Serial secondary propulsion: in this patient with ulcerative colitis, barium suspension collected near the Crosby capsule (indicated by the arrow in frame 1 of this 30-second cine run) is seen to travel distally about 20 inches. It is propelled round a series of gut loops by the effects of gravity alternating with secondary responses to local distension. Distension results from gravitational pooling at the bottom of each loop.

TABLE I

PROPULSIVE ACTIVITY

\begin{tabular}{lll} 
& $\begin{array}{l}\text { Comparison } \\
\text { Group }\end{array}$ & $\begin{array}{l}\text { Ulcerative } \\
\text { Colitis } \text { Group }\end{array}$ \\
\hline No. in group observed & 7 & 7 \\
Serial secondary propulsion observed & 7 & 7 \\
Mean distance travelled (in.) & 14 & 13 \\
Mean space of movement (in./sec.) & 1 & 0.66 \\
Wave propulsion observed & 3 & 4 \\
Mean distance travelled (in.) & 6 & 4 \\
Mean speed of movement (in./sec.) & 0.5 & 0.33
\end{tabular}

tation' and what we have called, from the apparent mechanism of its development, 'serial secondary propulsion' combines the features of both their 'progressive segmentation' and their 'rush peristalsis'.

Another form of propulsion that was regularly seen in the upper intestinal tract was by the direct progression of a single annular constriction down the gut towards the ileum. These single propulsive waves were slower and less common than serial secondary movements, occurring about half as often and moving over shorter distances at about half the speed (Table I). Once again, they were one third slower in ulcerative colitis than in the comparison groups. This pattern of propulsion does not appear to have been seen by McLaren et al. They may not have distinguished it in practice from their conception of progressive segmentation, but it is so characteristic and so constantly a feature of animal experiments where inflated balloons have been used that this seems unlikely. It is probably an abnormal movement of the gut associated with the Crosby capsule and its tubes.

INTRALUMINAL PRESSURE STUDIES These studied activity at rest and when the gut was stimulated.

Resting activity Motor activity capable of raising the intraluminal pressure of the upper intestinal tract was found to be present about $42 \%$ of the time of observation at rest in the four psoriasis subjects, whose gastrointestinal tracts must be regarded as functionally normal (Table II). It was present for $45 \%$ of the time in the anaemic patients and for $36 \%$ of the time after partial gastrectomy, an overall mean of $41 \%$ for these three principal comparative groups, in which the figures for the duodenum and the jejunum were similar. In the 14 patients with ulcerative colitis activity was present for $39 \%$ of the resting time and neither the site not the severity of the condition, as judged either clinically or by reference to the mucosal biopsy, affected the proportions.

In about two-thirds of the psoriatic and anaemic patients part of the resting activity took the form of rhythmic runs of pressure peaks lasting up to one minute at intervals of about two minutes (Fig. 5). This must probably be regarded as normal under the conditions of this study and a similar proportion of rhythmic activity was observed in ulcerative 
TABLE II

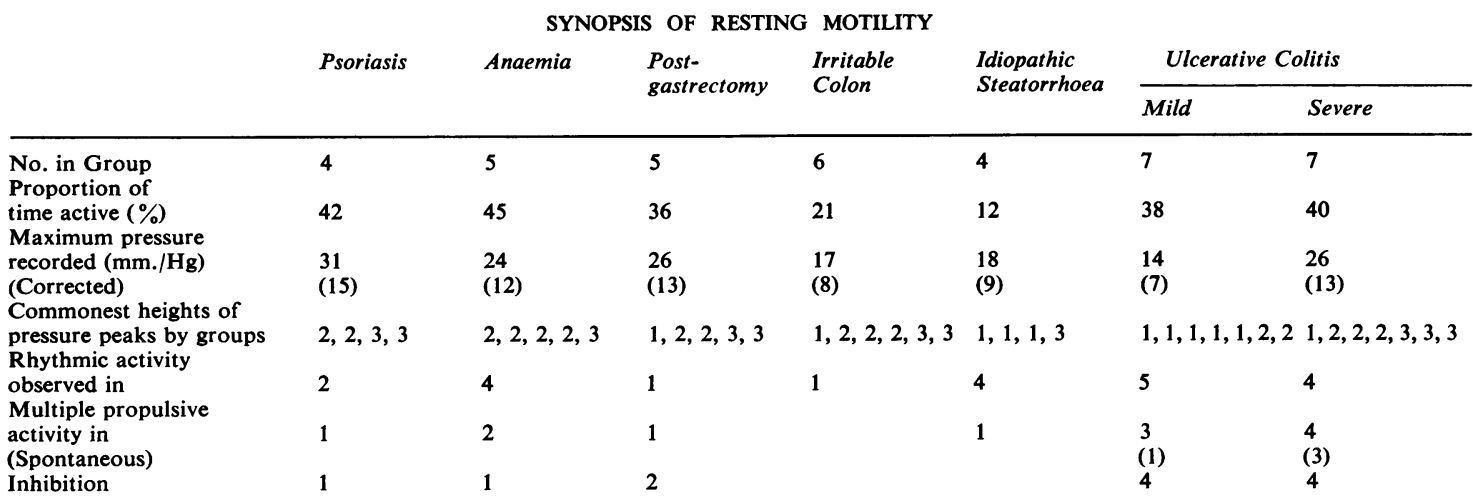

colitis and in steatorrhoea. Among the irritable colon and post-gastrectomy patients, on the other hand, less than one-fifth showed any sign of rhythmic activity.

In about $80 \%$ of the psoriatic, anaemic, and postgastrectomy groups, the commonest levels of the pressure peaks were found between 5 and $20 \mathrm{~mm}$. $\mathrm{Hg}$ (groups 2 and 3), with maximum pressures of about $26 \mathrm{~mm}$. $\mathrm{Hg}$. Ten per cent of the isolated pressure peaks in the psoriasis and anaemia groups lasted for five seconds or more, and $18 \%$ in the postgastrectomy group (Fig. 6).

The ulcerative colitis group contained $7 \%$ of peaks of more than five seconds' duration. In severe cases the other values were closly similar to the comparative groups, but during remissions the level of activity was substantially lower. The mean maximum pressure in mild colitis fell to $14 \mathrm{~mm}$. Hg, while in more than $70 \%$ of the patients the commonest level of peaks was less than $5 \mathrm{~mm}$. $\mathrm{Hg}$, much below that of the comparison groups $(\mathrm{P}=<0.005)$.
The other two groups also showed some degree of abnormality. In irritable colon, although the commonest levels of pressure peaks were similar to those of the comparison groups, only $21 \%$ of the resting time was spent in activity and the maximum

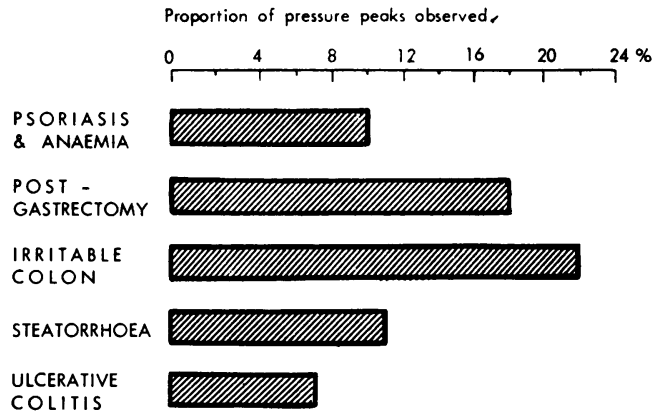

FIG. 6. Proportion of pressure peaks exceeding five seconds duration.

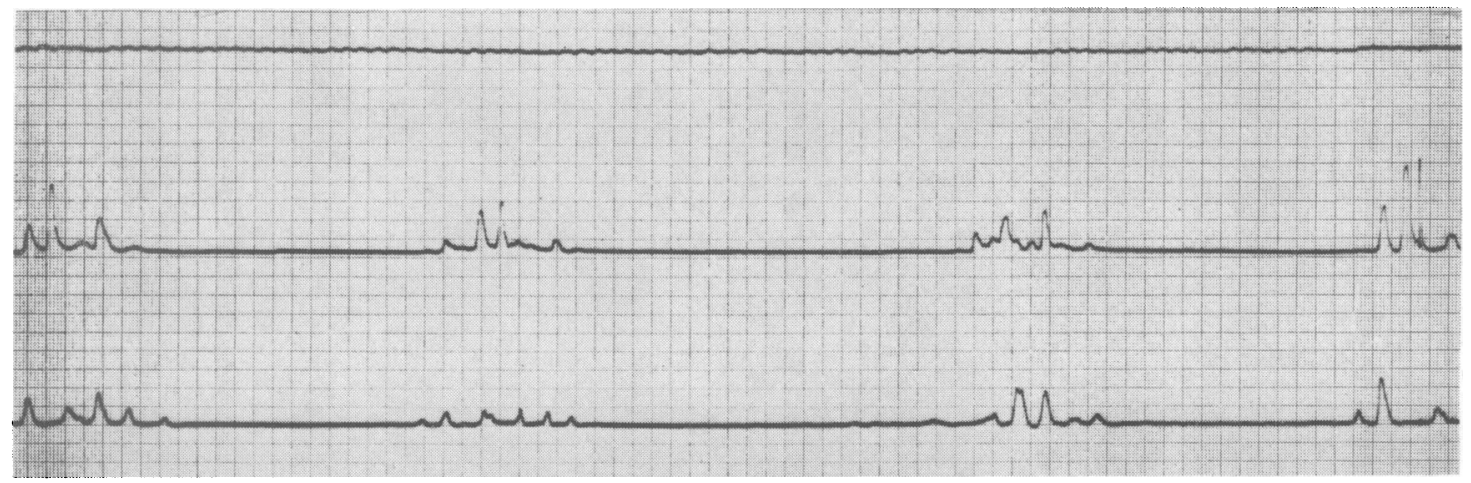

FIG. 5. Rhythmic activity: The upper channel records respiratory movement, the lower records pressures from the Crosby capsule, and the middle channel represents pressures from an open-ended tube $1.5 \mathrm{~cm}$. proximal to the capsule.

In about two-thirds of the normal and ulcerative colitis groups part of the resting activity took the form of rhythmic runs of pressure peaks. In this instance they occur at intervals of one and a half to two minutes and last about 30 seconds. 
peaks were down to $17 \mathrm{~mm}$. Hg. Statistical analysis shows that such falls, even to half the normal figure, are not fully significant in this small group $(P=$ 0.075 ), but they cannot be ignored. Of the pressure peaks in this group, $22.5 \%$ were present for five seconds or longer.

In idiopathic steatorrhoea activity was present at rest for only $12 \%$ of the time and here the difference from the comparative groups is significant at the $1 \%$ level. These patients also had a mean maximum pressure of $17 \mathrm{~mm} . \mathrm{Hg}$ and in three-quarters of them the commonest levels of their peaks were less than $5 \mathrm{~mm}$. Hg (group 1). Too little activity was observed to be sure of the proportion of contractions continuing beyond five seconds, but the figure appears to be about $11 \%$.

Gut stimulation During the first minute after the injection of $10 \mathrm{ml}$. of water at room temperature the proportion of time spent in activity rose by about $30 \%(\mathrm{P}=<0 \cdot 1)$ in all but one of the comparative groups (Table III). The sole exception was the postgastrectomy group, where the times of activity after water and saline were extended by $70 \%(P=0.05)$. Neither normal saline nor $2 \%$ glycine solution had any significant effect on activity in any group. Neither water, saline, nor glycine injections affected the maximum or commonest levels of pressure in any of the comparative groups, and the location of the capsule appeared to be of no importance.

In the ulcerative colitis group as a whole the responses to water and normal saline injections were not significantly different either from the resting figures or from one another. Nevertheless, the maximum heights of all pressure peaks in the duodenum were significantly lower than those in the jejunum in both mild and severe cases $(P=$ $<0.05$ ) and the commonest levels of peaks everywhere were lower in remittent than in severe cases $(P=<0.005)$, as they had been at rest. The effects of water and saline injections on the duration of activity in the jejunum were greater in mild cases than in severe ones $(P=0.05)$.

Hypertonic saline $(5 \%)$, which was given to a total of eight subjects from all groups, increased the mean proportion of time spent in activity from $43 \%$ to $70 \%$, but this rise is not statistically significant. Neither the maximum nor the commonest heights of the pressure peaks making up the response was affected.

Certain substances injected in solution in 10-ml. lots stimulated the gut to greatly increased activity as compared with water and normal saline. All of

\section{TABLE III}

INTESTINAL RESPONSE TO STIMULI

\begin{tabular}{|c|c|c|c|c|c|c|c|c|}
\hline \multirow[t]{2}{*}{ Stimulus } & & \multirow[t]{2}{*}{ Psoriasis } & \multirow[t]{2}{*}{ Anaemia } & \multirow{2}{*}{$\begin{array}{l}\text { Post- } \\
\text { gastrectomy }\end{array}$} & \multirow{2}{*}{$\begin{array}{l}\text { Irritable } \\
\text { Colon }\end{array}$} & \multirow{2}{*}{$\begin{array}{l}\text { Idiopathic } \\
\text { Steatorrhoea }\end{array}$} & \multicolumn{2}{|c|}{ Ulcerative Colitis } \\
\hline & & & & & & & Mild & Severe \\
\hline $\begin{array}{l}\text { Water } \\
\text { and } \\
\text { saline }\end{array}$ & $\begin{array}{l}\text { No. observed } \\
\text { Proportion of time active }(\%) \\
\text { Maximum pressure (mm. Hg) } \\
\text { Commonest pressure groups }\end{array}$ & $\begin{array}{l}6 \\
57 \\
9 \\
1,2,2,2,2\end{array}$ & $\begin{array}{l}10 \\
50 \\
17 \\
1,1,1,1,2 \\
2,2,3,4,4\end{array}$ & $\begin{array}{l}9 \\
60 \\
19 \\
1,2,2,2,2, \\
2,3,3,3\end{array}$ & $\begin{array}{r}1 \\
60 \\
18 \\
2\end{array}$ & $\begin{array}{l}8 \\
16 \\
5 \\
1,1,1,1,1 \\
1,2,4\end{array}$ & $\begin{array}{l}12 \\
53 \\
11 \\
1,1,1,1,1, \\
1,1,1,2,2, \\
2,2\end{array}$ & $\begin{array}{l}14 \\
45 \\
12 \\
1,1,2,2,2 \\
2,2,2,2,3 \\
3,3,3,3\end{array}$ \\
\hline Glycine & $\begin{array}{l}\text { No. observed } \\
\text { Proportion of time active }(\%) \\
\text { Maximum pressure (mm. Hg) } \\
\text { Commonest pressure groups }\end{array}$ & $\begin{array}{l}1 \\
\mathbf{0} \\
\mathbf{2} \\
\mathbf{1}\end{array}$ & $\begin{array}{l}4 \\
38 \\
20 \\
1,1,2,4\end{array}$ & $\begin{array}{r}1 \\
40 \\
4 \\
1\end{array}$ & & & $\begin{array}{l}5 \\
25 \\
8 \\
1,1,1,1,3\end{array}$ & $\begin{array}{c}2 \\
30 \\
7 \\
1,3\end{array}$ \\
\hline $\begin{array}{l}\text { Hyper- } \\
\text { tonic } \\
\text { glucose }\end{array}$ & $\begin{array}{l}\text { No. observed } \\
\text { Proportion of time active (\%) } \\
\text { Maximum pressure (mm. Hg) } \\
\text { Commonest pressure groups }\end{array}$ & $\begin{array}{l}3 \\
78 \\
16 \\
3,3,3\end{array}$ & $\begin{array}{l}4 \\
97 \\
48 \\
2,4,4,4\end{array}$ & $\begin{array}{l}4 \\
95 \\
49 \\
3,3,4,4\end{array}$ & $\begin{array}{r}1 \\
100 \\
50 \\
4\end{array}$ & $\begin{array}{l}3 \\
69 \\
16 \\
2,2,2\end{array}$ & $\begin{array}{l}6 \\
69 \\
18 \\
2,2,3,3,4 \\
4\end{array}$ & $\begin{array}{l}7 \\
80 \\
28 \\
1,2,3,3,3 \\
4,4\end{array}$ \\
\hline Cysteine & $\begin{array}{l}\text { No. observed } \\
\text { Proportion of time active (\%) } \\
\text { Maximum pressure (mm. Hg) } \\
\text { Commonest pressure groups }\end{array}$ & $\begin{array}{l}2 \\
90 \\
42 \\
3,4\end{array}$ & $\begin{array}{l}4 \\
94 \\
48 \\
3,4,4,4\end{array}$ & $\begin{array}{l}4 \\
85 \\
43 \\
2,3,4,4\end{array}$ & & $\begin{array}{c}3 \\
51 \\
38 \\
3,3,4\end{array}$ & $\begin{array}{l}6 \\
87 \\
32 \\
2,3,3,4,4 \\
4\end{array}$ & $\begin{array}{l}4 \\
58 \\
27 \\
3,3,3,3\end{array}$ \\
\hline $\begin{array}{l}\text { Ascorbic } \\
\text { acid }\end{array}$ & $\begin{array}{l}\text { No. observed } \\
\text { Proportion of time active (\%) } \\
\text { Maximum pressure (mm. Hg) } \\
\text { Commonest pressure groups }\end{array}$ & $\begin{array}{l}2 \\
73 \\
30 \\
3,3\end{array}$ & $\begin{array}{l}2 \\
87 \\
27 \\
3,4\end{array}$ & & & $\begin{array}{r}1 \\
67 \\
42 \\
4\end{array}$ & $\begin{array}{r}1 \\
33 \\
6 \\
2\end{array}$ & $\begin{array}{r}1 \\
33 \\
8 \\
3\end{array}$ \\
\hline $\begin{array}{l}\text { Firing } \\
\text { capsule }\end{array}$ & $\begin{array}{l}\text { No. observed } \\
5 \text { sec. response (mm. Hg) } \\
\text { Proportion of time sctive (\%) } \\
\text { Maximum pressure (mm. Hg) } \\
\text { Commonest pressure groups }\end{array}$ & $\begin{array}{c}3 \\
6 \\
30 \\
9 \\
1,2,3\end{array}$ & $\begin{array}{l}5 \\
17 \\
26 \\
23 \\
1,1,3,3,4\end{array}$ & $\begin{array}{l}5 \\
6 \\
36 \\
22 \\
1,1,2,3,4\end{array}$ & $\begin{array}{l}6 \\
19 \\
44 \\
37 \\
1,2,2,2,3, \\
4\end{array}$ & $\begin{array}{r}4 \\
26 \\
66 \\
34 \\
1,3,3,4\end{array}$ & $\begin{array}{l}7 \\
11 \\
47 \\
19 \\
1,2,2,2,3 \\
3,4\end{array}$ & $\begin{array}{l}7 \\
10 \\
51 \\
16 \\
1,1,1,2,2, \\
2,3\end{array}$ \\
\hline
\end{tabular}


them affected the duodenum and jejunum equally in the comparison groups.

Hypertonic glucose ( 25 or $50 \%$ solutions) raised the proportion of time active both in ulcerative colitis patients and in the comparison groups by about $60 \%(P=0.05)$ compared with water and saline (Fig. 7). Maximum pressures too were higher in the comparative groups $(P=<0.005)$ and in severe ulcerative colitis $(P=<0.01)$, where the difference was greater in the jejunum than in the duodenum $(P=0.02)$. Maximum pressures were not significantly increased in steatorrhoea or in mild ulcerative colitis. The commonest heights of pressure peaks were also increased after hypertonic glucose. In the psoriatic, anaemic, and post-gastrectomy groups after normal saline $76 \%$ of peaks were less than $10 \mathrm{~mm}$. Hg but after the glucose $89 \%$ of them were more than $10 \mathrm{~mm}$. $\mathrm{Hg}(\mathbf{P}=<0.005)$. In the irritable colon and steatorrhoea groups the difference was even higher. In ulcerative colitis increase in the commonest height of pressure peaks was confined to mild cases and was most marked in the jejunum.

Cysteine solution ( $2 \%$ ), unlike glycine, raised the level of activity in the comparison groups to much the same degree as hypertonic glucose $(P=<0.005)$ (Fig. 8) and in steatorrhoea it increased both the maximum pressures and the commonest level of peaks by substantially more than the glucose $(P=0.05)$. In ulcerative colitis, injection of cysteine increased the proportion of time of activity compared

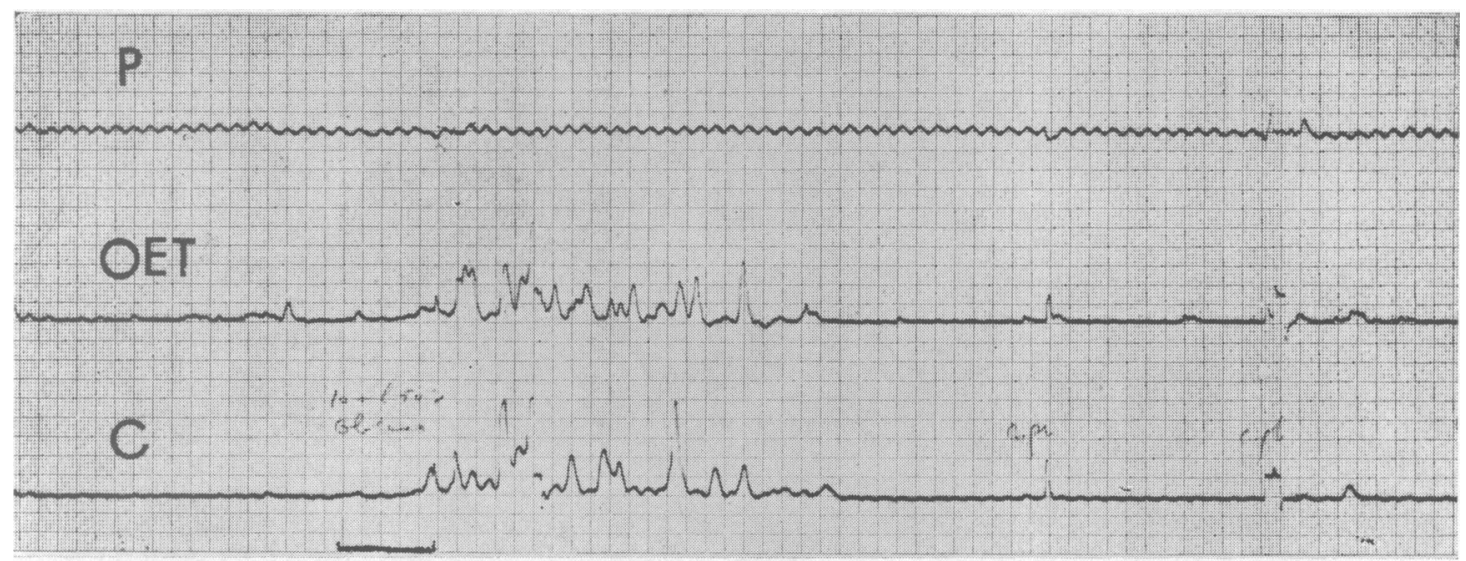

FIG. 7. The response of the small intestine to hypertonic glucose: the lowest tracing represents pressure changes transmitted through the Crosby capsule after the introduction of $10 \mathrm{ml}$. of $50 \% \mathrm{glucose} 4 \mathrm{~cm}$. proximal to the capsule. The period of the injection is marked by the horizontal line.

Each of the $5 \mathrm{~mm}$. squares on the tracing represents four seconds' duration and $10 \mathrm{~mm}$. $\mathrm{Hg}$ in height.

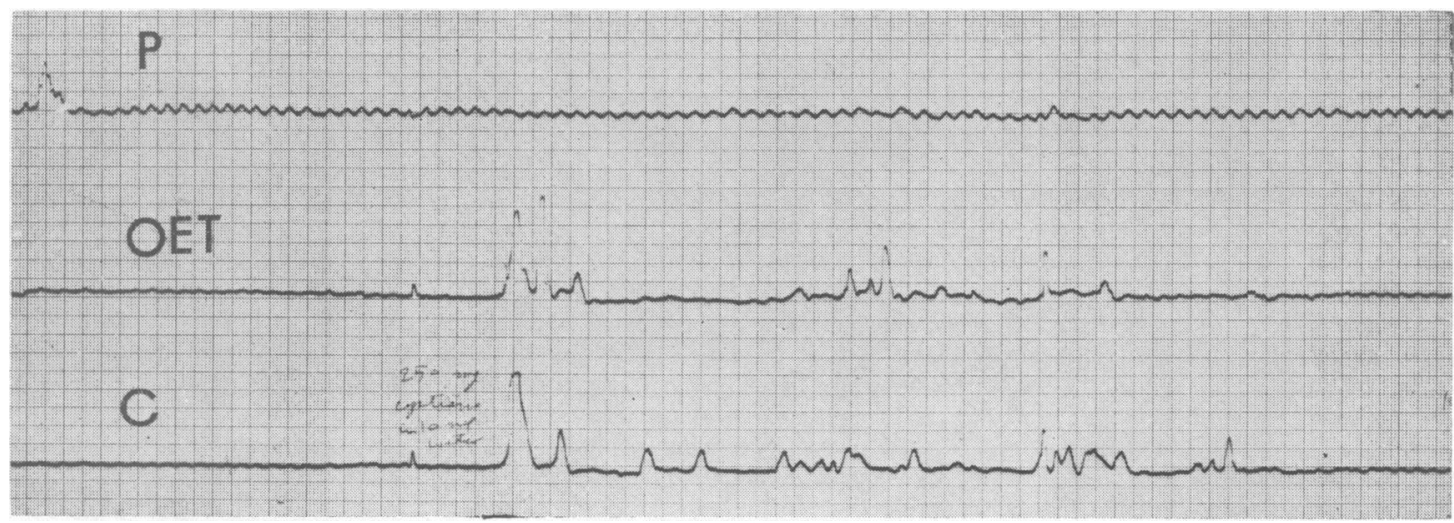

FIG. 8. The response of the small intestine to $2 \%$ cysteine solution: the lowest tracing represents pressure changes transmitted through the Crosby capsule after the introduction of $10 \mathrm{ml}$. of $2 \%$ cysteine solution $4 \mathrm{~cm}$. proximal to the capsule. The period of the injection is marked by the horizontal line. 

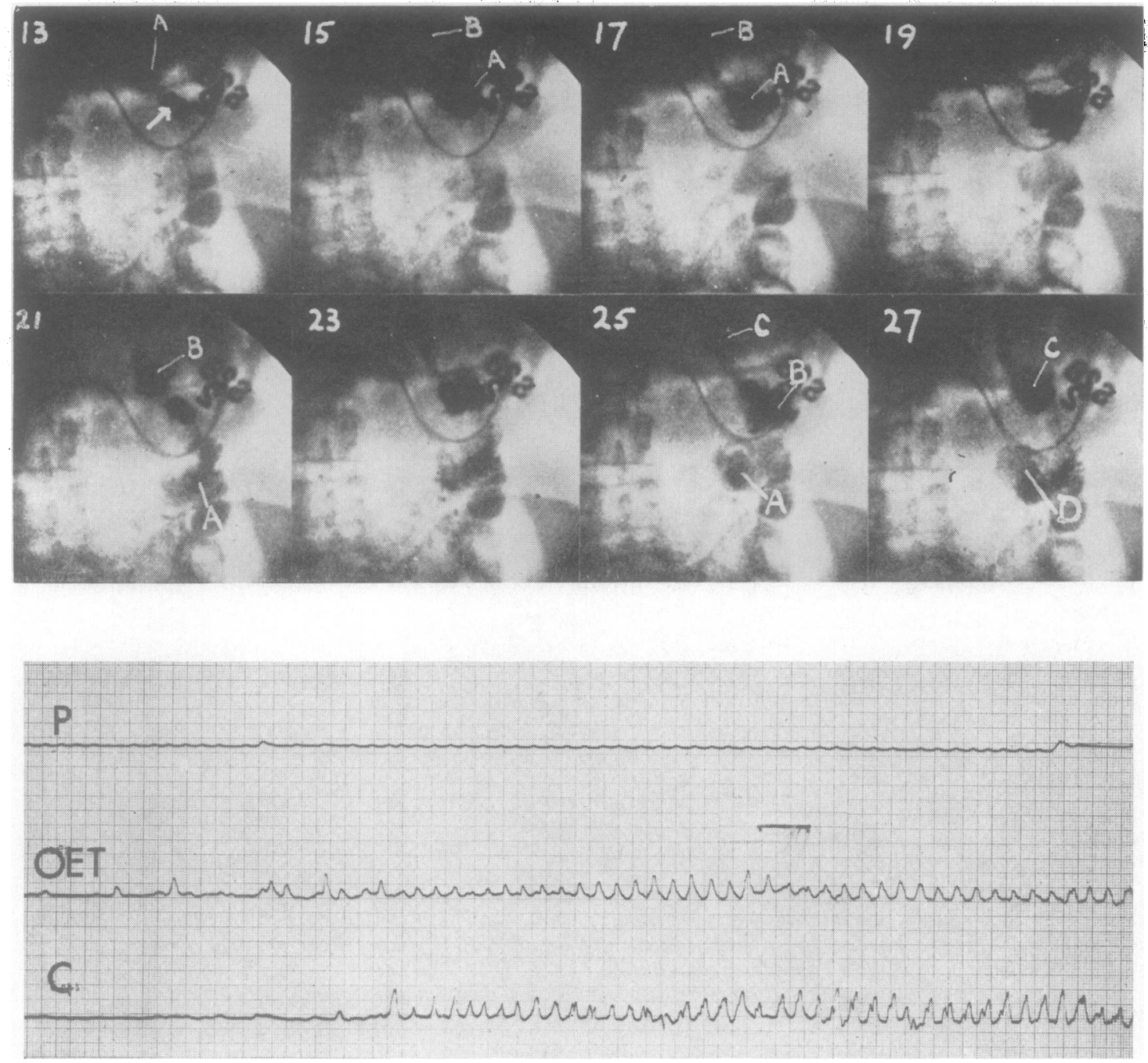

FIG. 9. (a and b) Multiple propulsive wave activity: the upper channel of the pressure tracing shows respiratory movement, the lower records pressures from the Crosby capsule, and the middle channel represents pressures from an openended tube $1.5 \mathrm{~cm}$. proximal to the capsule. Each of the $5 \mathrm{~mm}$. squares on the tracing represents four seconds of duration and $10 \mathrm{~mm} . \mathrm{Hg}$ in height.

The eight frames of cine, with approximately two seconds between them, occupy the period of 12 seconds indicated by the horizontal line. In the first of them, frame 13, the position of the capsule is marked by the arrow. The remains of a barium meal are visible in the descending colon. A series of pressure peaks of 10 to $20 \mathrm{~mm}$. $\mathrm{Hg}$ have been occurring alternately on the two channels for one and a half minutes when the cine observations start. Shortly before frame 13 continuous slow instillation of $10 \mathrm{ml}$. barium suspension begins $4 \mathrm{~cm}$. proximal to the capsule. The first part of this injection, shown at $A$, moves down the gut preceded and followed by rings of contraction, which are seen to reach the capsule in frames 13 and 19. The second part of the barium injection, $B$, appears in frame 19, passes the capsule in frames 21 and 23 and is followed by a contraction in frame 25 . A third portion of barium, $C$, becomes visible in frame 25 and reaches the capsule in frame 27. It is clear that the pressure peaks on the tracing are related to the passage of contraction rings and that the pressure of the barium propelled by them is about 3-4 $\mathrm{mm}$. Hg. Propulsion ceases, and the barium collects, at $D$, about three inches distal to the capsule. 
Upper intestinal motility in ulcerative colitis, idiopathic steatorrhoea, and the irritable colon syndrome 333

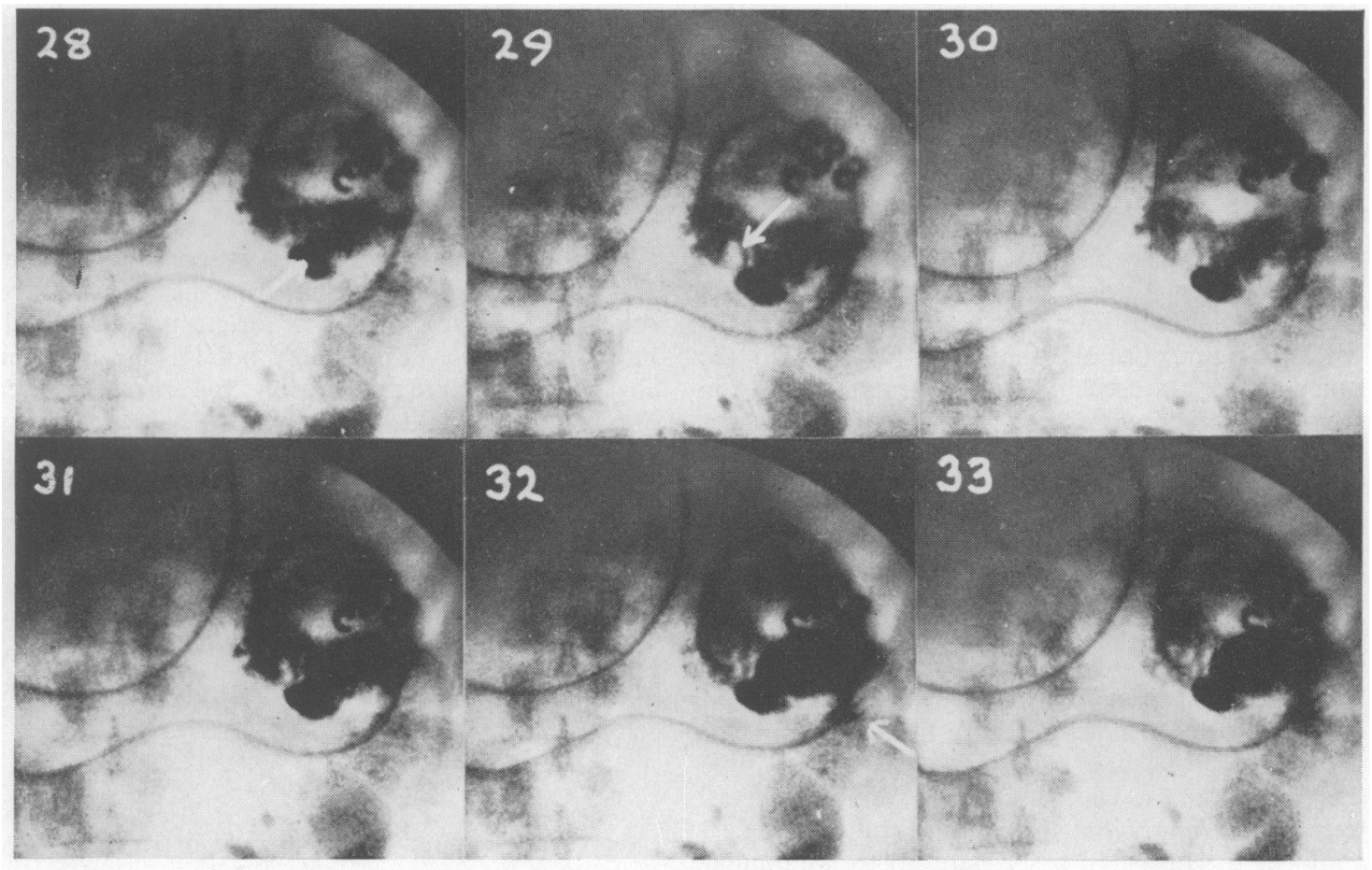

FIG. 10. ( $\mathrm{a}$ and b) The response of the jejunum to the trauma of biopsy: the upper channel on the pressure tracing shows pressures at a point $1.5 \mathrm{~cm}$. proximal to the capsule, marked by an arrow in frame 28 , the first picture of the cine series. At frame 29 air was injected to clear the capsule of water and is visible (arrowed) just proximal to the capsule. At frame 30 ( $F$ on chart) the capsule is fired by suction on the tube and about a second later a contraction begins at the capsule which spreads proximally to involve the open-ended tube in frame 32 and reaches $40 \mathrm{~mm}$. $\mathrm{Hg}$. This forces the barium distal to it further down the gut (arrow, frame 32). 
with water and saline by $50 \%$ and once again the increase in jejunal activity was greater in mild than in severe cases $(\mathbf{P}=<0.01)$. Cysteine also doubled the mean maximum height of pressure peaks in all cases though pressures in the duodenum remained at only half the jejunal level.

Ascorbic acid (2\%) solution increased the proportion of time spent in activity in four individuals from the comparative groups by about $60 \%$ but this figure is doubtfully significant when compared with that for normal saline $(P=0.075)$. On the other hand, it caused highly significant increases in the maximum pressures recorded and in the commonest levels of pressure peaks $(P=<0.005)$. Ascorbic acid did not appear to stimulate activity in any respect in the two ulcerative colitis patients who received it.

FUNCTIONAL RESPONSES In some subjects characteristic spells of rhythmic propulsive activity were seen from time to time in which pressure peaks of between 10 and $40 \mathrm{~mm} . \mathrm{Hg}$ at a frequency of 11 or 12 per minute occurred alternately at the two tube tips $1.5 \mathrm{~cm}$. apart. These 'multiple propulsive waves' were shown by cineradiographic studies (Fig. 9 $a$ and b) to consist of a series of 30 to 60 annular constrictions, each about half an inch wide and three-quarters of an inch apart, moving down short lengths of the gut at a mean speed of about a quarter of an inch a second. They were almost certainly aimed at the elimination of the capsule as a foreign body. Multiple propulsive waves were seen only five times in all in the comparison groups $(22 \%$ of observations) and then only after some form of external stimulation (Table II). In ulcerative colitis they occurred twice as often, the difference being due to four bouts of multiple propulsive activity which came on at rest, three of them in the jejunum. The difference between the ulcerative colitis and comparative groups in respect of these spontaneous bursts of propulsive irritability is doubtfully significant, but it is worth noting that three out of the four occurred in severely affected patients.

Overactivity of the gut, such as that following stimulant injections or bouts of multiple propulsive activity, sometimes resulted in a period of inhibition, during which rhythmic activity was lost and the response to further stimulation was weak or absent. Inhibition of this kind, lasting up to 30 minutes, occurred in $57 \%$ of patients with ulcerative colitis (Table II), almost three times as often as in the comparative groups $(P=0.05)$, and was equally common in mild and severe cases.

BIOPSY TRAUMA The trauma of the biopsy knife was often followed by a contraction of the gut which reached its peak within five seconds (Fig. $10 \mathrm{a}$ and b). The mean height of this immediate response, about $11 \mathrm{~mm} . \mathrm{Hg}$, was the same in all groups after jejunal biopsy and in all but two after duodenal biopsy. The mean level of the three immediate responses to duodenal biopsy observed in patients with steatorrhoea and the irritable colon syndrome was $50 \mathrm{~mm}$. $\mathrm{Hg}$ and here the difference from the mean of the other responses was significant at the $1 \%$ level. Patients in these groups may possibly be in some slight danger of perforation by rupture after duodenal biopsy.

The firing of the Crosby capsule was also associated with a four-fold increase in the proportion of time active as compared with the injection of water and saline in the four patients with steatorrhoea $(P=0.05)$ (Table III). Apart from these instances, the trauma of the biopsy caused no increase in the duration of activity nor was there any difference afterwards in the mean maximum heights or in the commonest heights of pressure peaks.

\section{DISCUSSION}

CHOICE OF PARAMETERS It is now a truism to say that intraluminal pressure records bear no direct or consistent relationship to gut motility. The height of the pressures that are developed in the gut is largely controlled by the interaction of two quite separate features of intestinal muscular function, its motor activity and the luminal resistance. Neither of them can be isolated for exact measurement, but changes in the level of each can sometimes be inferred from the pressure tracing in the light of cineradiographic comparisons.

Pressure peaks associated with duodeno-jejunal activity appear radiographically to be produced in one of two ways. They may either be transmitted indirectly from the gut wall by an increase in the pressure of gut contents unable to escape by reason of the luminal resistance, or they may arise directly, through the power of the gut's contractions forcing its mucosa into the hole in the capsule or open-ended tube. Although the higher pressures mostly seem to be due to this plunger-like action of the mucous membrane, pressures below about $25 \mathrm{~mm}$. $\mathrm{Hg}$ can be produced in either way.

Before two peaks can be compared in terms of gut motility, it is necessary to know whether they represent direct or indirect compression of the tube tip. At present this can only be determined with certainty by means of cineradiography. As an approximation, since the higher pressures are usually caused by direct action of the gut wall and so are independent of the luminal resistance, the 
maximum heights recorded may be regarded as indicating the gut's potential of muscular activity. The commonest height of the pressure peaks, on the other hand, may reflect the results of either direct or indirect activity. When the commonest height of peaks is increased and at the same time their maximum pressures are increased in proportion, the information given by this parameter may be equivocal. On the other hand, when the two sets of parameters change in different degrees or even in different directions, the commonest heights of the pressure peaks are probably reflecting the luminal resistance.

PROPULSIVE ACTIVITY The cineradiographic studies indicate that the difference between the localized shuttling of contents and their systematic propulsion along the small intestine depends mainly on the interrelationship of three factors. These are the duration and strength of the primary contraction, the length of the secondary interval, most commonly four to five seconds, and the level of the luminal resistance.

Primary contractions in the upper small intestine may last from two to seven seconds. If the primary contraction produces a high intraluminal pressure, either because of its own excessive strength or through the obstructive effect of high luminal resistance, the secondary response tends to occur earlier. This is particularly so in ulcerative colitis.

When a primary contraction is prolonged, or the secondary interval in shortened, the return route of the displaced contents is blocked. They must then travel onwards up or down the gut, depending on the direction in which they were first propelled, each length of newly distended gut contracting after four or five seconds and sending them further on. Eventually, at some point they either fail to provoke a response or, with a weak luminal resistance, they run so far ahead of the last contraction that it has time to relax before they are forced back against it and propulsion ceases.

From the variations that have been observed among the groups in the number of pressure peaks of different durations, it appears that in normal subjects about $10 \%$ of peaks last longer than five seconds (Fig. 3). Similar proportions are found in ulcerative colitis $(7 \%)$ and in idiopathic steatorrhoea $(11 \%)$. This means that over $90 \%$ of primary gut contractions in these three classes of subject are likely to have relaxed before a secondary response can develop to the distension that they cause in adjacent sections; the gut contents that have been displaced by them can thus be shuttled back to their starting point.

In the post-gastrectomy group the proportion of small-intestinal pressure peaks exceeding five seconds' duration is increased to $18 \%$ and in the irritable colon syndrome it is over $22 \%$. In these two groups, and particularly in irritable colon, there is a definite reduction of duodeno-jejunal motility. It follows that they must either experience some degree of small gut stasis, which is contrary to the usual belief, or they must operate a higher ratio of propulsive to localized activity than normal to keep the gut contents moving. The fact that twice the normal number of their pressure peaks last as long as, or longer than, the mean secondary interval, and so may initiate a serial propulsive movement, offers a possible explanation of how this comes about. It seems clear from this finding that the dysfunction favouring diarrhoea in the irritable colon syndrome, despite the normal appearances in the small gut, is already present as high up as the duodenum.

CLINICAL CORRELATION Among the patients with psoriasis and anaemia, in two of the comparative groups that seem for the most part to form a homogeneous unit at rest, there is motor activity of some sort for about 25 seconds of each minute. This may be expected to reach a mean maximum pressure of about $13 \mathrm{~mm} . \mathrm{Hg}$ in that time and the commonest heights of the peaks that compose it will be between 5 and $20 \mathrm{~mm}$. $\mathrm{Hg}$ with $10 \%$ of them lasting longer than five seconds. This constitutes the standard background of motility under the conditions of this study and governs the relative proportions of localized and propulsive activity in normal intestinal function.

The partial gastrectomy group is similar in all respects at rest, except in the higher proportion of pressure peaks lasting over five seconds, apparently representing an increased potential for propulsive activity.

In steatorrhoea at rest there is motor activity only for some seven seconds of each minute, reaching a mean maximum height of about $9 \mathrm{~mm}$. $\mathrm{Hg}$ and most commonly operating at pressures of less than $5 \mathrm{~mm}$. $\mathrm{Hg}$. This pattern of function must logically result either from a neurogenic inhibition of both phasic and tonic activity in the small intestine, or from the combined effects of such inhibition and muscular weakness. Although the response of this group to simple distension is only slightly greater than its resting level of activity, there is little evidence to support the idea of weakness. Under the influence of chemical stimuli like cysteine and ascorbic acid the levels of motility are raised till they resemble those of the normal comparison groups, and after the trauma of biopsy they are almost twice as high. On the other hand, it it not possible to relate the 
defective absorption that is found in this group specifically to the loss of luminal resistance or to the reduction of motor activity. Either or both may be contributory factors.

In the irritable colon group the proportion of activity is halved and its maximum pressure is also reduced, while the commonest heights of the pressure peaks remain normal. These findings also suggest a primary inhibition of phasic activity in the upper intestinal tract rather than any weakness of the gut wall, but there is nothing to indicate the fall of luminal resistance that would accompany a generalized depression of muscular tone. There is also as a general rule no defect of small gut absorption. This evidence of motor inhibition appears to represent an attempt by the central nervous system to offset the tendency to excessive propulsion.

In ulcerative colitis, although the pressures are low, the time of activity is not reduced. This suggests a widespread muscular weakness rather than inhibition, and the low level of the commonest pressure peaks supports the impression of a diminished luminal resistance resulting from it.

In severe ulcerative colitis activity appears to be normal in all measurable respects and in these patients it is probable that the muscular weakness has been masked by increased irritability of the diseased intestine in the presence of the Crosby capsule and recording tubes. The higher incidence of spontaneous multiple propulsive activity supports this explanation. Also, in the ulcerative colitis group, increased activity is commonly followed by a period of inhibition involving one or more of the rhythmic cycles of contraction (Table II) and suggesting undue fatiguability of the bowel. This would tend to restore the proportion of activity during the resting period without reducing the mean level of the remaining pressures.

If the apparent normality of function in severe ulcerative colitis is due to the presence of the Crosby capsule, the gut's behaviour in mild cases must be typical of the group under natural conditions. Thus, apart from the mechanical irritation of the capsule, the gut in ulcerative colitis may even be hyposensitive to other physico-chemical stimuli like cysteine and ascorbic acid. This, together with the muscle weakness, probably accounts for the slower rate of propulsion (Table I). The low levels of working pressure and luminal resistance in ulcerative colitis would lead to stasis if they were not partially compensated for by the shortening of the secondary interval (Fig. 2), increasing the chance of a propulsive effect from each normal primary contraction.

In the absence of any indication either of increased propulsion or of a reduced duration of activity in ulcerative colitis, these patients' defects of absorption are most directly related to the level of the commonest intraluminal pressure peaks. In so far as their malabsorption may be due to changes in small gut motility, therefore, it appears to be due mainly to a lowering of the luminal resistance.

\section{SUMMARY}

In order to identify motility factors associated with malabsorption, upper intestinal activity has been examined by means of intraluminal pressure recording at rest and after certain stimuli in 38 subjects. These included 14 patients with ulcerative colitis, four with steatorrhoea, and 20 with other conditions having normal intestinal mucosae and normal xylose excretion. Fourteen of the patients were also observed with short spells of sequence radiography at one frame per second.

Four parameters of comparison were used: the proportion of time active, the maximum heights of pressure peaks, the commonest heights of peaks, and the duration of all isolated peaks at rest. The relationship of these to different aspects of gut function are discussed and it is argued that, while the first two are indices of phasic activity, the third may provide information about the tonic activity representing luminal resistance. A method is indicated of using the fourth to distinguish the relative probabilities of localized and propulsive activity following a contraction of the gut.

The proportion of intestinal propulsion appears to be normal or low in ulcerative colitis and these patients show some weakness of phasic activity and fatiguability, especially in the duodenum. The proportion is normal in steatorrhoea. The proportion of propulsive activity is doubled after partial gastrectomy and in the irritable colon syndrome, though the duration of activity shows a compensatory reduction in these conditions.

The only motility factor that is altered in steatorrhoea and ulcerative colitis, but not in the groups with normal xylose excretion, is the luminal resistance. This is the factor most likely to play a part in small gut absorption.

We would like to offer our thanks to Professor L. J. Witts for the facilities of the Nuffield Department of Medicine, to Dr. S. C. Truelove for permission to investigate patients under his care, and for his helpful criticism and encouragement in the preparation of this paper, to Dr. G. M. Ardran for his advice and to Mr. M. S. Tuckey for his assistance as technician and radiographer.

This study was supported in part by the United States Public Health Service (Grant A.5123) and by the Medical Research Council. 
Upper intestinal motility in ulcerative colitis, idiopathic steattorrhoea, and the irritable colon syndrome 337

\section{REFERENCES}

Groisser, V. W., and Farrar, J. T. (1962). Effect of intestinal motility on the absorption of sodium in man. Amer. J. dig. Dis., 7, 57-68.

McLaren, J. W., Ardran, G. M., and Sutcliffe, J. (1950). Radiographic studies of duodenum and jejunum in man. J. Fac. Radiol. (Lond.), 2, 148-164.
Ritchie, J. A., Ardran, G. M., and Truelove, S. C. (1962). Motor activity of the sigmoid colon of humans. Gastroenterology, 43, 642-668.

Salem, S. N., Truelove, S. C., and Richards, W. C. D. (1964). Smallintestinal and gastric changes in ulcerative colitis. Brit. med. J., 1, 394-398.

Vartio, T. (1963). D-xylose tolerance test. Ann. Med. int. Fenn., 52, 183-189. 